\title{
Development of Subcutaneous Implants of Controlled Release Formulations of Carvedilol for Sustained Blood Pressure Reduction in Experimental Models of Hypertension
}

\author{
Desarrollo de implantes subcutáneos de liberación controlada de Carvedilol para la reducción \\ sostenida de la presión arterial en modelos experimentales de hipertensión arterial
}

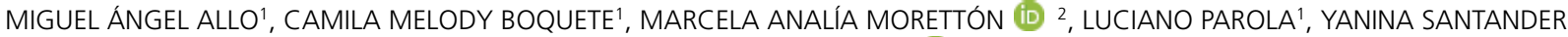
PLANTAMURA ${ }^{1}$, FACUNDO MARTÍN BERTERA ${ }^{1,3}$, DIEGO ANDRÉS CHIAPPETTA (iD ${ }^{2}$, CHRISTIAN HÖCHT (iD) ${ }^{1,3}$
\end{abstract}

\begin{abstract}
Background: The aim of this study was the development and pharmacokinetic/pharmacodynamic evaluation of the in vivo release of subcutaneous implants of carvedilol capable of providing stable tissue levels in experimental models of hypertension.

Methods: The subcutaneous implants were prepared with poly (epsilon-caprolactone) (PCL) and different proportions of the SoluPlus (SP) hydrophilic polymer (300:0; 250:50; 150:150 and 50:250 mg) loaded with $100 \mathrm{mg}$ carvedilol. The plasma profile and the effect on systolic blood pressure (SBP) after subcutaneous implantation of each formulation was evaluated in male spontaneously hypertensive rats (SHR).

Results: The PCL:SP 50:250 and 150:150 formulations provided levels ranging from 100 to $200 \mathrm{ng} / \mathrm{mL}$ and the PCL:SP 250:50 and 300:0 formulations provided lower concentrations of carvedilol ranging from 0 to $100 \mathrm{ng} / \mathrm{mL}$ during the treatment period. Spontaneously hypertensive animals treated with the PCL:SP 50:250 y 150:150 implants presented a significant decrease in SBP (PCL:SP 50:250: $\triangle$ PAS: $-36.6 \pm 2.0 \mathrm{~mm} \mathrm{Hg}$; PCL:SP150:150: $-35.7 \pm 2.2 \mathrm{mmHg}$; $<<0.05$ vs. baseline values)

Conclusions: The incorporation of the SoluPlus hydrophilic polymer in PC:SP 150:150 and 50:250 implants increases the release of carvedilol, since it provides plasma concentrations ranging from 100 to $200 \mathrm{ng} / \mathrm{ml}$, resulting in a sustained reduction of indirect SBP in SHR.
\end{abstract}

Key words: Carvedilol/administration \& dosage - Nanoparticles/Therapeutics use - Delayed-Action Preparations - Blood Pressure - Rats

\section{RESUMEN}

Objetivo: El objetivo del presente estudio fue el desarrollo y la evaluación farmacocinética y farmacodinámica de la liberación in vivo de implantes subcutáneos de carvedilol capaces de aportar niveles tisulares estables en modelos experimentales de hipertensión arterial.

Material y métodos: Se prepararon implantes subcutáneos de poli (epsilon-caprolactona) (PCL) con diferentes proporciones del polímero hidrofílico SoluPlus (300:0; 250:50; 150:150 y 50:250 mg) cargados con $100 \mathrm{mg}$ de carvedilol. Se evaluó el perfil plasmático y el efecto sobre la presión arterial sistólica (PAS) luego del implante de cada formulación en el tejido subcutáneo de ratas espontáneamente hipertensas (REH) macho.

Resultados: Las formulaciones PCL:SP 50:250 y 150:150 aportaron niveles en el rango de 100-200 ng/mL. Las formulaciones PCL:SP 250:50 y 300:0 aportaron concentraciones inferiores de carvedilol comprendidas en el rango de los 0-100 ng/mL durante el transcurso del tratamiento. Los animales espontáneamente hipertensos tratados con PCL:SP 50:250 y 150:150 experimentaron un descenso significativo de la presión arterial sistólica (PCL:SP 50:250: $\triangle$ PAS: $-36,6 \pm 2,0 \mathrm{mmHg}$; PCL:SP150:150:-35,7 $\pm 2,2 \mathrm{mmHg} ; \mathrm{p}<0,05$ vs. basal).

Conclusiones: La incorporación del polímero hidrofílico SoluPlus en los implantes PCL:SP 150:150 y 50:250 favorece un incremento de la liberación de carvedilol, ya que aporta concentraciones plasmáticas del ß-bloqueante que aseguran una reducción sostenida de la PAS indirecta en animales espontáneamente hipertensos.

Palabras claves: Carvedilol/administración y dosificación - Presión sanguínea - Preparaciones de acción retardada - Ratas

REv ARGENT CARDIOL 2020;88:125-129. http://dx.doi.org/10.7775/rac.v88.i2.17472

Received: 12/14/2019 - Accepted: 03/05/2020

Address for reprints: Miguel Allo - Cátedra de Farmacología. Facultad de Farmacia y Bioquímica - Universidad de Buenos Aires - Junín 956, (C1113AAD) Buenos Aires, ARGENTINA - Phone: +(54-11)-4964-8265 - Fax: +(54-11)-4508-3645 - E-mail: migueblues89@hotmail.com

${ }^{1}$ University of Buenos Aires, School of Pharmacy and Biochemistry, Department of Pharmacology.
${ }^{2}$ University of Buenos Aires, School of Pharmacy and Biochemistry, Department of Pharmaceutical Technology.
${ }^{3}$ University of Buenos Aires, School of Pharmacy and Biochemistry, Institute of Pathophysiology and Clinical Biochemistry, Buenos Aires, Argentina. 


\section{Abbreviations}

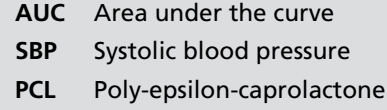

SHR Spontaneously hypertensive rats

SP Soluplus

\section{INTRODUCTION}

Hypertension is still the leading cause of mortality worldwide and represents the main risk factor for cardiovascular disease. (1) Prevention of cardiovascular events associated with hypertension requires not only effective blood pressure reduction, but also the 24hour attenuation of blood pressure variability. (2-5) A key aspect of antihypertensive therapy is to achieve and maintain persistent blood pressure control during 24 hours to ensure attenuation of the blood pressure morning surge. (6)

Carvedilol is a nonselective $\beta$-blocker with vasodilating activity secondary to $\alpha 1$-adrenergic blockade and additional pleiotropic actions, including antioxidant, anti-inflammatory and antiapoptotic effects. (7) Compared to conventional $\beta$-blockers, carvedilol has demonstrated better hemodynamic and metabolic profile. (8) However, one limitation of carvedilol for the treatment of hypertension is its low oral bioavailability and rapid systemic clearance, which adversely affect sustained blood pressure reduction and blood pressure variability. In this setting, carvedilol encounters first-pass metabolism after oral administration resulting in low bioavailability (about 25\%) and short elimination half-life of only $2 \mathrm{~h}$. (9)

In view of these facts, several research groups have developed different formulations of carvedilol to increase bioavailability and prolong the duration of the ß-blocker in the organism. In this context, carvedilol nanoparticles have been developed using chitosan or Eudragit ${ }^{\circledR}$ RS100 polymer. $(10,11)$ These formulations have been shown to improve the pharmacokinetic characteristics, although the impact on the control of hemodynamic variables and on prevention of target organ damage have not been evaluated. $(10,11)$ In our laboratory, we have developed subcutaneous implants of carvedilol with the goal of establishing the usefulness of these pharmaco-technical developments in optimizing the prevention of target organ damage associated with experimental hypertension.

The aim of this study was the development and pharmacokinetic/pharmacodynamic evaluation of the in vivo release of different subcutaneous implants of carvedilol in spontaneously hypertensive rats (SHR).

\section{METHODS}

Subcutaneous implants of carvedilol

Subcutaneous implants were prepared with poly (epsiloncaprolactone) (PCL) and different proportions of SoluPlus (SP) hydrophilic polymer (300:0; 250:50; 150:150 and 50:250 $\mathrm{mg}$ ) loaded with $100 \mathrm{mg}$ carvedilol using the melt-moldingcompression method. To prepare the PCL and SP implants loaded with carvedilol $100 \mathrm{mg}$, the polymers and the drug powder were mixed in different weight ratios, placed in an 11-mm diameter stainless steel mold and firmly compressed with a punch, then heated in a preheated oven $\left(70^{\circ} \mathrm{C}, 1 \mathrm{~h}\right)$ and compressed $(0.713 \mathrm{~kg} / \mathrm{cm} 2)$ during the entire heating treatment. Next, the molds were cooled ( $\left.{ }^{\circ} \mathrm{C}, 30 \mathrm{~min}\right)$ and, finally, the samples were removed to obtain disk-shaped implants (11 mm diameter).

\section{Animals}

Spontaneously hypertensive male rats $(22-220 \mathrm{~g})$ were trained during 2 weeks for systolic blood pressure (SBP) measurement using the previously described indirect tailcuff method. (12) After estimating baseline SBP for 3 days, the rats were anesthetized with intraperitoneal ketamine $(75 \mathrm{mg} / \mathrm{kg})$ and xylazine $(10 \mathrm{mg} / \mathrm{kg})$ and one of the following subcutaneous implants loaded with carvedilol was placed under the skin at the back of the neck: PCL:SP 300:0 (n $=5)$, PCL:SP 250:50 (n = 5), PCL:SP 150:150 ( $\mathrm{n}=5) \mathrm{y}$ PCL:SP 50:250 $(n=5)$. Every day during the next 2 weeks after implantation, indirect SBP was measured and $100 \mu \mathrm{L}$ of venous blood was drawn from the lateral vein of the tail to determine carvedilol levels.

Systolic blood pressure was measured by the indirect tail-cuff method using a sphygmomanometer coupled to a Grass 7C polygraph (Grass Instrument Co., Quincy, MA USA). The animals were first conditioned in a thermostated room for $60 \mathrm{~min}$ and then transferred to a special acrylic tube heated at $37 \pm 1{ }^{\circ} \mathrm{C}$ to measure SBP. Indirect SBP was calculated as the average of six separate measurements during the same day.

Plasma levels of carvedilol were measured by liquid chromatography with fluorometric detection using an analytical method validated in the laboratory. (13)

\section{Pharmacokinetic analysis}

The pharmacokinetic time course of carvedilol plasma levels was analyzed applying a noncompartmental model with first-order elimination. The pharmacokinetic parameters: area under the curve (AUC), maximum plasma concentration (Cmax), time to maximum plasma concentration (tmax), and elimination half-life (t1/2) were estimated using TOPFIT 2.0 software (Dr Karl Thomae Gmbh, Schering AG, Germany).

\section{Statistical analysis}

The Kolmogorov-Smirnov test was used to evaluate normal distribution of data and study variables. Results were expressed as mean \pm standard error of the mean (SEM). Statistical comparison between treatment groups was performed using one-way ANOVA followed by Tukey's method as post-hoc test using GraphPad Prism version 6.0 (GraphPad Software, San Diego, California, USA). A p value $<0.05$ was considered statistically significant.

\section{Ethical considerations}

The experiments with animals were carried out in accord- 
ance with the "Guide for the Care and Use of Laboratory Animals" (NIH publication 85-3, 1985 Revision) and were approved by the Ethics Committee of the School of Pharmacy and Biochemistry of the University of Buenos Aires (EXP-UBA No. 0037832/2019).

\section{RESULTS}

The different disk-shaped carvedilol implants had a diameter of $11 \mathrm{~mm}$ (Figure 1). The insertion of carvedilol implants under the skin at the back of the neck was successful in all cases with no signs of pain or behavioral changes in the animals during the assessment period.

The different types of carvedilol implants developed provided relatively stable levels of the $\beta$-blocker for two weeks (Figure 2). The PCL:SP 50:250 and 150:150 formulations provided levels ranging from 100 to $200 \mathrm{ng} / \mathrm{mL}$ for most of the 2 -week follow-up period (Figure 2). On day 12 after the implants were placed, carvedilol plasma concentrations were $174 \pm$ $39 \mathrm{ng} / \mathrm{mL}$ and $113 \pm 20 \mathrm{ng} / \mathrm{mL}$ with PCL:SP 50:250 and 150:150 implants, respectively (Figure 2). The PCL:SP 250:50 and 300:0 formulations provided lower concentrations of carvedilol, ranging from 0 to 100 $\mathrm{ng} / \mathrm{mL}$ during the treatment period (Figure 2).

Table 1 shows the main pharmacokinetic parameters of carvedilol plasma profiles in the different experimental groups. The PCL:SP 50:250 formulation was associated with higher carvedilol Cmax and AUC compared with the other implants studied (Table 1). Carvedilol bioavailability after subcutaneous implant with the PCL:SP 150:150 formulation was higher than that measured in the PCL:SP 250:50 and 300:0 groups (Table 1).

Follow-up of indirect SBP measurement after subcutaneous insertion of the carvedilol implant showed a significant decrease of SBP from day 3 to day 15 in SHR treated with PCL:SP 50:250 and PCL:SP 150:150 formulations (Figure 3). In contrast, groups treated with PCL:SP 250:50 and PCL:SP 300:0 implants did not experience a significant decrease in indirect SBP compared with baseline values (Figure 3).
Fig. 1. Photograph of a subcutaneous implant of carvedilol developed in the laboratory.
Fig. 2. Carvedilol plasma levels after placement of different types of implants in SHR. Each data point is represented as mean \pm SEM.
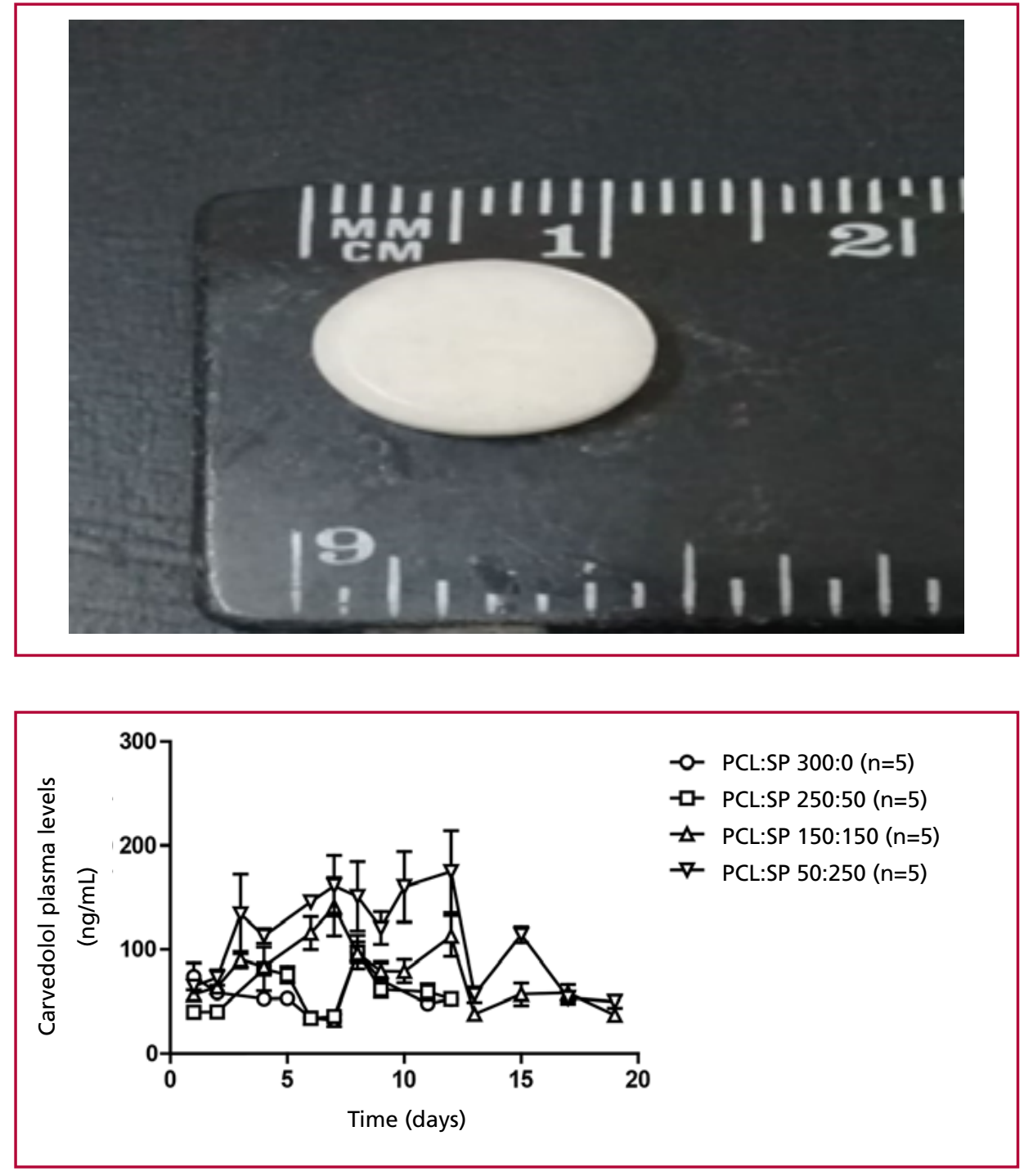


\section{DISCUSSION}

In the present study, the development of subcutaneous carvedilol implants using different proportions of PCL and SP polymers has proved to be an effective pharmaco-technical strategy for maintaining sustained levels of carvedilol for more than 2 weeks. Those implants with a higher proportion of SP provided higher stable plasma concentrations compared to PCL:SP 250:50 and PCL:SP 300:0 formulations, allowing a sustained reduction of indirect SBP in SHR.

The effective prevention of target organ damage associated with hypertension requires effective control of both central blood pressure and blood pressure variability without generating adverse metabolic effects. (8) Overactivation of the sympathetic nervous system plays a key role in the development and maintenance of hypertension, so modulating sympathetic overactivity represents an important goal of treatment. (14) Despite the recognized importance of the sympathetic nervous system in the development of hypertension, ß-blockers are no longer recommended as first-line treatment due to clinical trial evidence suggesting reduced cardioprotection as a result of their limited effects on central blood pressure and blood pressure variability, and the development of adverse metabolic effects. (15-17) However, these limitations are typical of conventional $\beta$-blockers, especially atenolol, and do not seem to be extrapolated to vasodilator ß-blockers with pleiotropic action, such as carvedilol. (8) Clinical trial results and evaluations conducted in experimental models of hypertension have estab- lished that chronic treatment with carvedilol is more effective than with atenolol in reducing central blood pressure and blood pressure variability, hemodynamic properties that suggest greater protection from target organ damage associated with hypertension. (8)

Despite the improved hemodynamic profile of carvedilol, a limitation of this vasodilator $\beta$-blocker is its rapid systemic elimination, affecting its ability to maintain a sustained reduction in blood pressure for 24 hours. (9) A clinical measure that quantifies the 24-hour therapeutic coverage provided by an antihypertensive agent is the trough-to-peak ratio, which represents the relationship between maximal $\mathrm{BP}$ decrease and its reduction before the administration of the next dose. (6) Thus, a higher trough-to-peak index indicates a longer duration of action affording an optimal therapeutic coverage during the early morning hours with lower risk of adverse events. (6)

While a trough-to-peak ratio around 0.5 to 0.75 is acceptable, a ratio closer to 1 ensures that the antihypertensive effect is maintained throughout the dosing interval. (6) Comparative clinical trials have demonstrated that antihypertensive agents with a troughto-peak ratio of 0.9 ensure greater attenuation of the early morning blood pressure surge than those with a trough-to-peak ratio of around 0.5. (18) In the case of carvedilol, the trough-to-peak ratio of commercially available immediate-release and extended-release formulations is less than 0.8. (6)

In this context, we have considered the need to develop extended-release formulations of carvedilol us-

\begin{tabular}{|lcccc|} 
& PCL:SP & PCL:SP & PCL:SP & PCL:SP \\
& $\mathbf{3 0 0 : 0}$ & $\mathbf{2 5 0 : 5 0}$ & $\mathbf{1 5 0 : 1 5 0}$ & $\mathbf{5 0 : 2 5 0}$ \\
\hline tmáx $(\mathrm{h})$ & $200 \pm 6$ & $120 \pm 17$ & $208 \pm 28$ & $168 \pm 35$ \\
\hline $\mathrm{C} \max (\mathrm{ng} / \mathrm{mL})$ & $109 \pm 7$ & $112 \pm 12$ & $168 \pm 13 \# \&$ & $243 \pm 4^{*} \# \&$ \\
\hline $\mathrm{AUC}(\mu \mathrm{g} / \mathrm{mL} . \mathrm{h})$ & $17.2 \pm 0.4$ & $14.5 \pm 0.5$ & $35.1 \pm 1.5 \# \&$ & $46.9 \pm 0.1^{*} \# \&$ \\
\hline $\mathrm{t} 1 / 2(\mathrm{~h})$ & $125 \pm 27$ & $198 \pm 56$ & $129 \pm 37$ & $91 \pm 5$ \\
\hline
\end{tabular}

AUC: Area under the curve. ${ }^{*} p<0.05$ vs. PCL:SP 150:150; \# $p<0.05$ vs. PCL:SP 250:50; \& $p<0.05$ vs. PCL:SP 300:0.

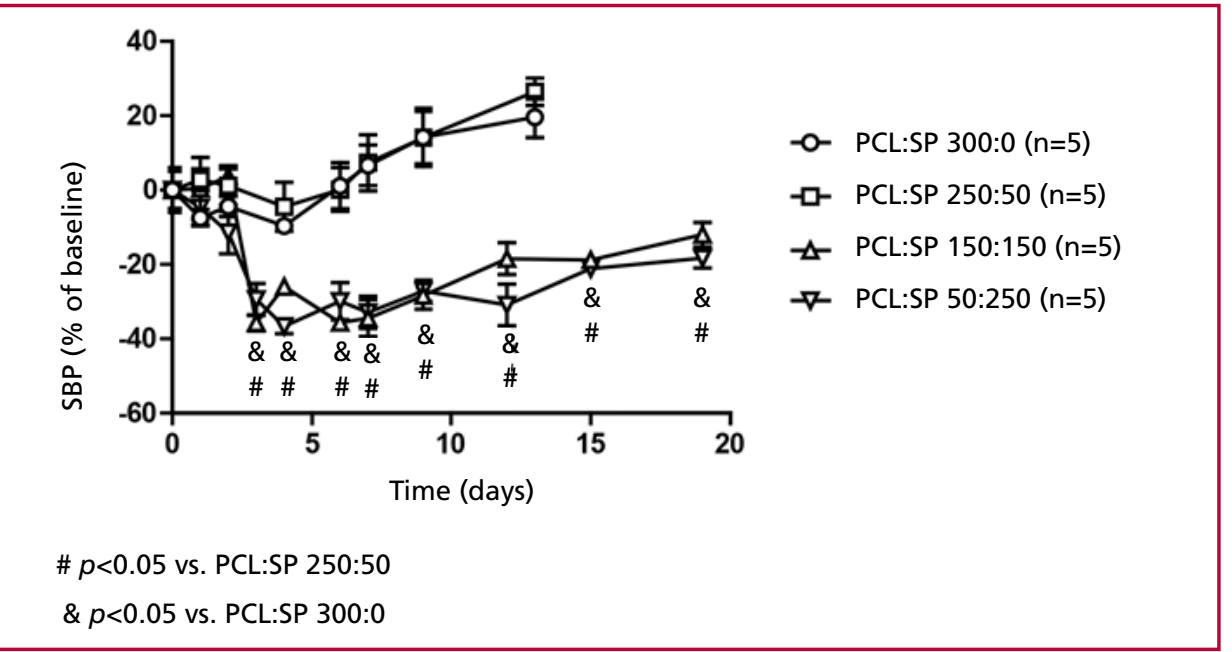

Fig. 3. Changes in indirect SBP in SHR after placement of the different subcutaneous implants of carvedilol.

Table 1. Pharmacokinetic parameters for the different carvedilol formulations 
ing melt-molding-compression of the active ingredient with polymers. PCL and SP polymers represent two of the main excipients used in the development of extended-release formulations. $(19,20)$ Since PCL limits the access of the surrounding aqueous medium into the implant, which slows down the dissolution of the drug and thus decreases its release, we evaluated the impact of replacing a fraction of PLC by SP. SP is a polymer with amphiphilic properties that improves dissolution and bioavailability of many poorly soluble drugs. (20) The addition of this polymer to the formulation facilitates solvent penetration since it accelerates the release process. Therefore, an increase in carvedilol plasma levels could be expected proportionally to the increase in the ratio of SP in the implant. In this context, the pharmacokinetic analysis of carvedilol plasma profiles of the different experimental groups establishes that the formulations with higher SP content (PCL:SP 50:250 and PCL:SP 150:150) provide significantly higher plasma concentrations compared with the PCL:SP 250:50 and PCL:SP 300:0 formulations.

\section{CONCLUSIONS}

The phamocodynamic evaluation of the different subcutaneous carvedilol implants showed a significant decrease of indirect SBP in SHR treated with PCL:SP 50:250 and PCL:SP 150:150 formulations. These preliminary findings establish that the development of sustained-release formulations of carvedilol that ensure stable plasma levels in the range of $100-200 \mathrm{ng} /$ $\mathrm{mL}$ would represent a rational therapeutic strategy for the optimization of the experimental treatment of hypertension with carvedilol. Further research is needed to establish if maintaining a sustained reduction in SBP with subcutaneous implants of carvedilol provides a greater reduction in target organ damage in SHR compared with conventional immediate-release formulations.

\section{Conflicts of interest}

None declared.

(See authors' conflicts of interest forms on the website/ Supplementary material)

\section{Acknowledgments}

This study received a grant from the Secretaría de Ciencia y Técnica (SeCyT), University of Buenos Aires, Argentina. (Proyecto UBACyT 2016 20020150100142BA). Diego Chiappetta and Marcela Moretton are career investigators of CONICET

\section{REFERENCES}

1. Sociedad Argentina de Cardiología. Consenso Argentino de Hipertensión Arterial. Rev Argent Cardiol 2018; 86 (Suppl 2): 1-53. 2. Meredith PA. A chronotherapeutic approach to effective blood pressure management. J Clin Hypertens 2002;4(4 Suppl 1):15-9. https://doi.org/10.1111/j.1524-6175.2002.01035.x

3. Su DF, Miao CY. Reduction of blood pressure variability: a new strategy for the treatment of hypertension. Trends Pharmacol Sci 2005; 26: 388-90. https://doi.org/10.1016/j.tips.2005.06.003

4. Parati G, Ochoa JE, Lombardi C, Bilo G. Blood pressure variability: assessment, predictive value, and potential as a therapeutic target. Curr Hypertens Rep 2015;17:537. https://doi.org/10.1007/ s11906-015-0537-1

5. Stergiou GS, Palatini P, Asmar R, Bilo G, de la Sierra A, Head G, y cols. Blood pressure monitoring: theory and practice. European Society of Hypertension Working Group on Blood Pressure Monitoring and Cardiovascular Variability Teaching Course Proceedings. Blood Press Monit 2018;23:1-8. https://doi.org/10.1097/ MBP.0000000000000301

6. Flack JM, Nasser SA. Benefits of once-daily therapies in the treatment of hypertension. Vasc Health Risk Manag 2011;7:777-87. https://doi.org/10.2147/VHRM.S17207

7. Dandona P, Ghanim H, Brooks DP. Antioxidant activity of carvedilol in cardiovascular disease. J Hypertens 2007;25:731-41. https://doi.org/10.1097/HJH.0b013e3280127948

8. Höcht C, Bertera FM, Del Mauro JS, Santander Plantamura Y, Taira CA, Polizio AH. What is the Real Efficacy of Beta-Blockers for the Treatment of Essential Hypertension? Curr Pharm Des. 2017;23:4658-77. https://doi.org/10.2174/1381612823666170608085 109

9. El-Say KM, Hosny KM. Optimization of carvedilol solid lipid nanoparticles: An approach to control the release and enhance the oral bioavailability on rabbits. PLoS One 2018;13:e0203405. https:// doi.org/10.1371/journal.pone.0203405

10. Sharma M, Sharma R, Jain DK, Saraf A. Enhancement of oral bioavailability of poorly water soluble carvedilol by chitosan nanoparticles: Optimization and pharmacokinetic study. Int J Biol Macromol 2019;135:246-60. https://doi.org/10.1016/j.jjbiomac.2019.05.162 11. Lal Pal S, Jana U, Mohanta GP, Manna PK. Preparation and Physico-Chemical Characterization of Carvedilol-Eudragit ${ }^{\circledR}$ RS100 Nanoparticles. World J Pharmaceut Res 2018;7:1436-51.

12. Del Mauro JS, Prince PD, Donato M, Fernandez Machulsky NH, Moretton MA, González GE, Bertera FM, Carranza A, Gorzalczany SB, Chiappetta DA, Berg G, Morales C, Gelpi RJ, Taira CA, Höcht C. Effects of Carvedilol or Amlodipine on Target Organ Damage in L-Name Hypertensive Rats: Their Relationship with Blood Pressure Variability. J Am Soc Hypertens2017;11:227-40. https://doi. org/10.1016/j.jash.2017.02.007

13. Wegmann M, Parola L, Bertera FM, Taira CA, Cagel M, Buontempo F, Bernabeu E, Höcht C, Chiappetta DA, Moretton MA. Novel carvedilol paediatric nanomicelle formulation: in-vitro characterization and in-vivo evaluation. J Pharm Pharmacol 2017;69:544-53. https://doi.org/10.1111/jphp.12605

14. Grassi G, Ram VS. Evidence for a critical role of the sympathetic nervous system in hypertension. J Am Soc Hypertens 2016;10:45766. https://doi.org/10.1016/j.jash.2016.02.015

15. Wiysonge CS, Bradley HA, Volmink J, Mayosi BM, Opie LH. Beta-blockers for hypertension. Cochrane Database Syst Rev 2017;1: CD002003. https://doi.org/10.1002/14651858.CD002003.pub5

16. Chen YJ, Li LJ, Tang WL, Song JY, Qiu R, Li Q, et al. First-line drugs inhibiting the renin angiotensin system versus other first-line antihypertensive drug classes for hypertension. Cochrane Database Syst Rev 2018;11:CD008170. https://doi.org/10.1002/14651858. CD008170.pub3

17. Dahlöf B, Sever PS, Poulter NR, Wedel H, Beevers DG, Caulfield M, et al.; ASCOT Investigators. Prevention of cardiovascular events with an antihypertensive regimen of amlodipine adding perindopril as required versus atenolol adding bendroflumethiazide as required, in the Anglo-Scandinavian Cardiac Outcomes Trial-Blood Pressure Lowering Arm (ASCOTBPLA): a multicentre randomised controlled trial. Lancet 2005;366: 895-906. https://doi.org/10.1016/ S0140-6736(05)67185-1

18. Gosse P, Neutel JM, Schumacher H, Lacourciere Y, Williams B, Davidai G. The effect of telmisartan and ramipril on early morning blood pressure surge: a pooled analysis of two randomized clinical trials. Blood Press Monit 2007;12:141-7. https://doi.org/10.1097/ MBP.0b013e3280b10bbd

19. Carcaboso AM, Chiappetta DA, Höcht C, Blake MG, Boccia MM, Baratti CM, Sosnik A. In vitro/in vivo characterization of meltmolded gabapentin-loaded poly(epsilon-caprolactone) implants for sustained release in animal studies. Eur J Pharm Biopharm 2008;70:666-73. https://doi.org/10.1016/j.ejpb.2008.05.031

20. Linn M, Collnot EM, Djuric D, Hempel K, Fabian E, Kolter K, Lehr CM. Soluplus ${ }^{\circledR}$ as an effective absorption enhancer of poorly soluble drugs in vitro and in vivo. Eur J Pharm Sci 2012;45:336-43. https://doi.org/10.1016/j.ejps.2011.11.025 